\title{
Optimal Placement of Shunt Connected Facts Device in a Series Compensated LT-Line
}

\author{
${ }^{1 *}$ Ponnam. Yellaiah, ${ }^{2 *}$ Sravan Kumar.Palarapu, ${ }^{3 \#}$ Kumar.Keshamoni \\ ${ }^{1 *}$ Asst. Professor Dept of EEE in SICET (JNTU-H), Hyderabad, India \\ ${ }^{2 *}$ Sr.Asst. Professor Dept of EEE in ASTRA (JNTU-H), Hyderabad, India (*Corresponding author) \\ ${ }^{3 \#}$ Asst. Professor Dept of ECE in RVRIET (JNTU-H), Hyderabad, India
}

\begin{abstract}
This paper deals with the optimal location and parameters of Unified Power Flow Controllers (UPFCs) in electrical power systems. The UPFC is one of the most promising FACTS devices in terms of its ability to control power system quantities. Shunt FACTS devices are used for controlling transmission voltage, power flow, reducing reactive losses, and damping of power system oscillations for high power transfer levels. In this paper the optimal location of a shunt FACT device is investigated for an actual line model of a transmission line having series compensation at the center. As one of the most promising FACTS devices in terms of its ability to control power system quantities, UPFC Effect of change in degree of series compensation on the optimal placement of the shunt FACTS device to get the highest possible benefit is studied. The results obtained shown that optimal placement of the shunt FACTS device varies with the change in the level of series compensation.
\end{abstract}

Key Words: Optimal placement, Shunt FACTS, Series compensation, Unified power flow controller (UPFC)...

\section{Introduction}

The flexible AC transmission system (FACTS) has received much attention in the last 2 decades. It uses high current power electronic devices to control the voltage, power flow, stability, etc. of a transmission system. FACTS technologies can essentially be defined as highly engineered power-electronics-based systems, integrating the control and operation of advanced power-semiconductor-based converters (or valves) with software-based information and control systems, which produce a compensated response to the transmission network that is interconnected via conventional switchgear and transformation equipment. FACTS devices can be connected to a transmission line in various ways, such as in series with the power system (series compensation), in shunt with the power system (shunt compensation), or both in series and shunt. For example, the static VAR compensator (SVC) and static synchronous compensator (STATCOM) are connected in shunt; static synchronous series compensator (SSSC) and thyristor controlled series capacitor (TCSC) are connected in series; thyristor controlled phase shifting transformer (TCPST) and unified power flow controller (UPFC) are connected in a series and shunt combination. In series compensation, the FACTS is connected in series with the power system. It works as a controllable voltage source. Series inductance occurs in long transmission lines, and when a large current flow causes a large voltage drop.

To compensate, series capacitors are connected. In shunt compensation, power system is connected in shunt with the FACTS. It works as a controllable current source. The term and definition of various FACTS devices are described in references [1]-[5]. The pressure associated with economical and environmental constraints has forced the power utilities to meet the future demand by fully utilizing the existing resources of transmission facilities without building new lines. FACTS devices are very effective and capable of increasing the power transfer capability of a line, as thermal limits permit, while maintaining the same degree of stability [3]-[9]. Numerous recent applications of FACTS have proven to be cost-effective, long-term solutions. With the improvements in current and voltage handling capabilities of the power electronic devices that have allowed for the development of Flexible AC Transmission System (FACTS), the possibility has arisen in using different types of controllers for efficient shunt and series compensation. Applying FACTS on a broad-scale basis for both local and. Shunt FACTS devices are used for controlling transmission voltage, power flow, reducing reactive losses, and damping of power system oscillations for high power transfer levels [5]-[8]-[9]. With the widespread and active consideration of the installation of FACTS controllers for better controllability.

\section{Shunt compensation is of two types:}

Shunt capacitive compensation: This method is used to improve the power factor. Whenever an inductive load is connected to the transmission line, power factor lags because of lagging load current. To compensate, a shunt capacitor is connected which draws current leading the source voltage. The net result is improvement in power factor. Shunt inductive compensation: This method is used either when charging the transmission line, or, when there is very low load at the receiving end. Due to very low, or no load, very low 
current flows through the transmission line. Shunt capacitance in the transmission line causes voltage amplification (Ferranti Effect). The receiving end voltage may become double the sending end voltage (generally in case of very long transmission lines). To compensate, In the case of a no-loss line, voltage magnitude at receiving end is the same as voltage magnitude at sending end: VS $=\mathrm{VR}=\mathrm{V}$. Transmission results in a phase lag $\delta$ that depends on line reactance X. shunt inductors are connected across the transmission lines

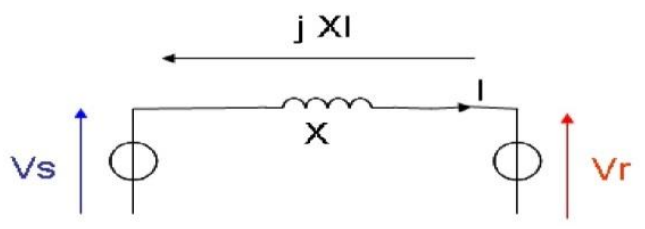

j XI

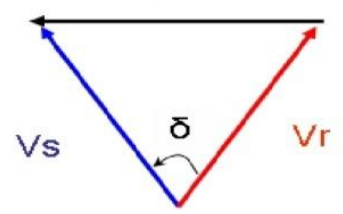

Fig 1. Series compensation.
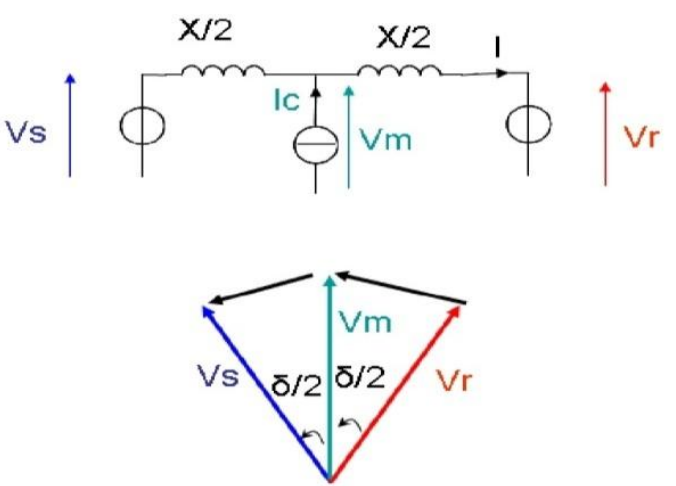

$\mathrm{V} s=\mathrm{V} m=\mathrm{V} r=\mathrm{V}$

Fig 2. Shunt compensation

In power systems, appropriate placement of these devices is becoming important. Improperly placed FACTS controllers fail to give the optimum performance and can even be counterproductive. Therefore, proper placement of these devices must be examined. This paper investigates the optimal location of shunt FACTS device in a series compensated transmission line to get the maximum possible benefit of maximum power transfer and system stability. The rating of a shunt FACT device is selected in such a way so as to control the voltage equal to sending end voltage at the bus of the shunt FACT device. It is observed that the optimal location of a shunt FACT device deviates from the center of the line towards the generator side with the increase in the degree of series Compensation. A series capacitor is placed at the center to get the maximum power transfer capability and compensation efficiency for the selected rating of the shunt FACTS device.

The shunt FACTS device is operated at that rating that is able to control the bus voltage of shunt FACTS device equal to sending end voltage so as to get the maximum possible benefit of maximum power transfer and stability under steady state conditions.

\section{Transmission Line Model}

In this study, it is considered that the transmission line parameters are uniformly distributed and the line can be modeled by a 2-port, 4-terminal networks as shown in Figure 1. This figure represents the actual line model. The relationship between sending end (SE) and receiving end (RE) quantities of the line can be written as: 


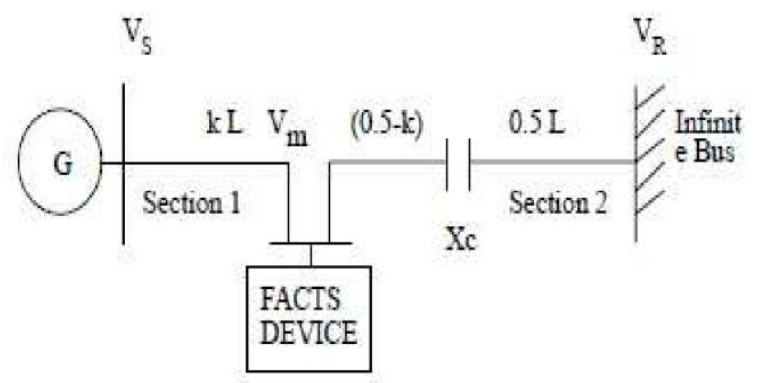

Fig 3. 2-Port, 4-terminal model of a transmission line

$$
\begin{aligned}
& V_{S}=A V_{R}+B I_{R} \\
& I_{S}=C V_{R}+D I_{R}
\end{aligned}
$$

The $\mathrm{ABCD}$ constants of a line of length $\mathrm{l}$, having a series impedance of $\mathrm{z} \Omega / \mathrm{km}$ and shunt admittance of $\mathrm{y} / \mathrm{km}$, are given by

$$
\begin{aligned}
& A=D=\cosh (\lambda l) B=Z_{C} \sinh (\lambda l) \\
& C=\sinh (\lambda l) / Z_{C}
\end{aligned}
$$

Where $V=\sqrt{z y}$ and $Z_{C}=\sqrt{z / y}$

The active and reactive power flows at the SE and RE of the line can be written as

$$
\begin{aligned}
P s & =C_{1} \cos (\beta-\alpha)-C_{2} \cos (\beta-\delta) \\
Q s & =C_{1} \sin (\beta-\alpha)-C_{2} \sin (\beta-\delta) \\
P_{R} & =C_{2} \cos (\beta-\delta)-C_{3} \cos (\beta-\alpha) \\
Q_{R} & =C_{2} \sin (\beta-\delta)-C_{3} \cos (\beta-\alpha)
\end{aligned}
$$

$$
\text { Where } \begin{aligned}
C_{1} & =A V s^{2} / B \\
C_{2} & =V s V_{R} / B \\
C_{3} & =A V_{R}^{2} / B \\
A & =A \angle \alpha, B=B \angle \beta \\
V_{R} & =V_{R} \angle 0, V_{S}=V_{S} \angle \delta
\end{aligned}
$$

It is clear from Eq. (6) that the RE power reaches the maximum value when the angle $\delta$ becomes $\beta$. However, the SE power PS of Eq. (4) becomes maximum at $\delta=(\Pi-\beta)$. In this study, a $345 \mathrm{kV}$ single circuit transmission line (450 km in length), is considered. It is assumed that each phase of line has a bundle of 2 conductors of size one million c-mils each and conductors are fully transposed. The series impedance and shunt admittance of the line are found to be $Z=(0.02986+j 0.2849) \Omega / \mathrm{km}$ and $\mathrm{y}=\mathrm{j} 3.989 \times 106 \mathrm{~S} / \mathrm{km}$, respectively, at $50 \mathrm{~Hz}$. The parameters are obtained using the PSCAD/EMTDC software package. The results of the line are presented in p.u. on a $100 \mathrm{MVA}, 345 \mathrm{kV}$ base [3].

\section{Series Compensated Transmission Line With Shunt Facts Devices}

Consider that the line is transferring power from a large generating station to an infinite bus and equipped with series capacitor at center and a shunt FACT device at point ' $m$ ' as shown in Figure 2. Parameter k is used to show the fraction of the line length at which the FACTS device is placed. The shunt FACTS device may be a SVC or STATCOM and is usually connected to the line through a step-down transformer as shown in Figures 3 and 4 . The transmission line is divided into 2 sections $(1 \& 2)$, and section 2 is further divided in subsections of length [(0.5-k) \& half-line length]. Each section is represented by a separate 2-port, 4-terminal network (similar to Figure 2) with its own ABCD constants considering the actual line model 


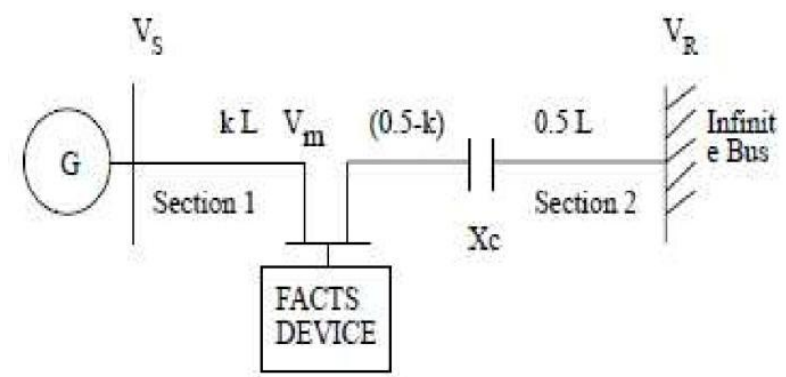

Fig 4. Series compensated transmission line with a shunt FACT device [3].
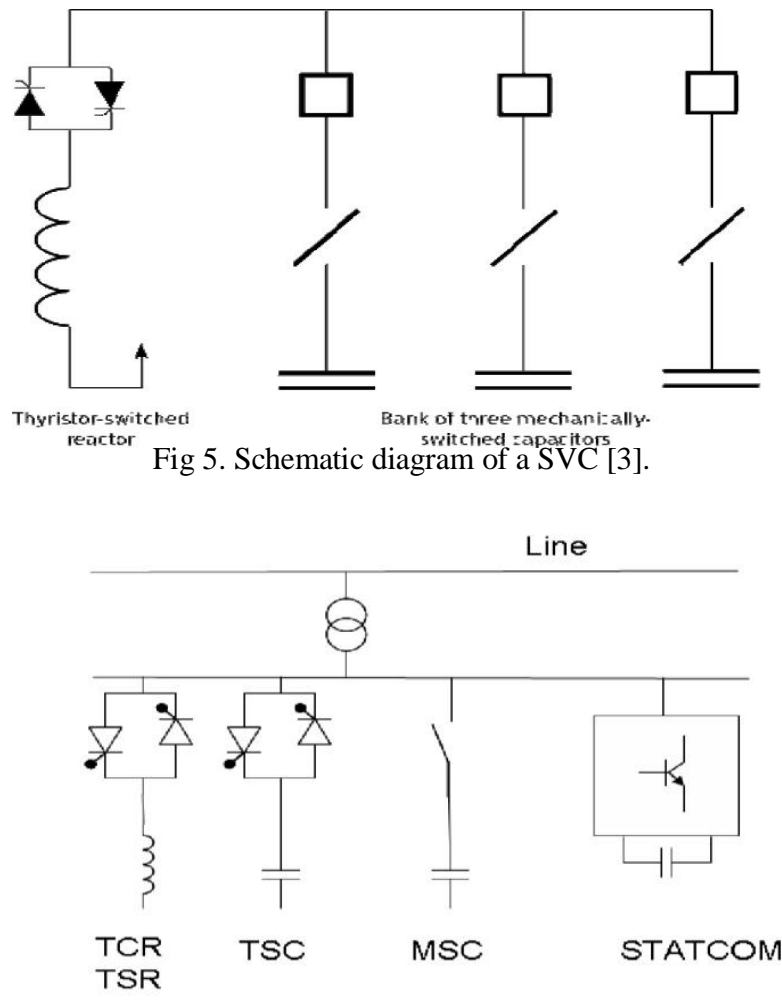

Fig 6. Examples of FACTS for shunt compensation.

It is supposed that the rating of the shunt FACTS device is large enough to supply the reactive power required to maintain a constant voltage magnitude at bus $\mathrm{m}$ and the device does not absorb or supply any active power.

\section{Maximum Power Transfer Capability}

For a simplified model, when there is no FACTS device connected to the line, maximum power transfer through the line is given by [3]:

$$
P=P_{m} \sin \delta
$$

Many researchers established that the optimal location of shunt FACTS device for a simplified model is at $\mathrm{K}=0.5$ when there is no series compensation in the line. For such cases maximum power transmission capability $(\mathrm{Pm})$ and maximum transmission angle $(\delta \mathrm{m})$ become double. However, for an actual line model power flow is given by Eqs. (4) and (6) instead of Eq. (9) and the above results may not be considered accurate. One of the objectives of this paper is to find the maximum power and corresponding location of shunt FACTS device for different series compensation levels $(\% \mathrm{~S})$ located at the center of the line. A sophisticated computer program was developed to determine the various characteristics of the system of Figure 2 using an actual model of the line sections. The constant of the same RE power of section (1) and SE power of section (2) (PR1 = PS2) is incorporated into the problem. In all cases, $\mathrm{VS}=\mathrm{VR}=\mathrm{VM}=1.0$ p.u. unless specified. The maximum power $\mathrm{Pm}$ and corresponding angle $\delta \mathrm{m}$ are prior determined for various values of location $(\mathrm{K})$. Figures 5-7 show the 
variation in maximum RE power ( PRm ), maximum sending end power, and transmission angle $(\delta \mathrm{m})$ at the maximum sending end power, respectively, against $(\mathrm{K})$ for different series compensation levels $(\% \mathrm{~S})$. It can be noticed from Figures 5 and 6 that PSm $>$ PRm for any series compensation level $(\% \mathrm{~S})$ because of the loss in the line. From Figure 5 it can be noted that when $\% \mathrm{~S}=0$ the value of PSm increases as the value of $(\mathrm{K})$ is increased from zero and reaches the maximum value of 18.5 p.u. at

$$
\begin{aligned}
& \mathrm{K}=0.45 \text { (but not at } \mathrm{K}=0.5 \text { ). Slope of } \\
& \text { the } \\
& P_{S}{ }^{m} \text { curve suddenly } \\
& \text { changes at } \mathrm{K}=0.45 \text { and the value of } \quad P_{S}{ }^{m} \text { decreases when }
\end{aligned}
$$

$\mathrm{K}>0.45$. A similar pattern for PRm can be observed from

Figure 6 when $(\% \mathrm{~S}=0)$. When series compensation in the line is taken into account, we observe that the optimal location of the shunt FACTS device will change and shifts towards the generator side. As seen from Figure 5 , when $\% \mathrm{~S}=15$ then $\mathrm{PSm}$ increases from 12.5 p.u. (at $\mathrm{K}=0$ ) to its maximum value 22 p.u. (at $\mathrm{K}=$ 0.375). When $\mathrm{K}$ is further increased then PSm decreases. It means that, for maximum power transfer capability, the optimal location of the shunt device will change when series compensation level changes. When $\% \mathrm{~S}=30$, the optimal location further shifts to the generator side and PSm increases from 15.2 p.u. (at $\mathrm{K}=0$ ) to its maximum value 26.8 p.u. (at $\mathrm{K}=0.3$ ).

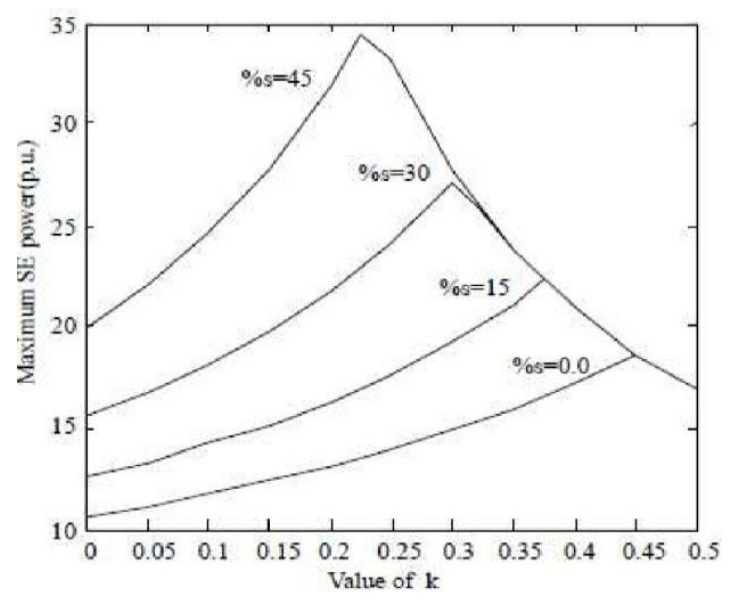

Fig 7. Variation in maximum SE power for diff. value of $\% \mathrm{~S}$.

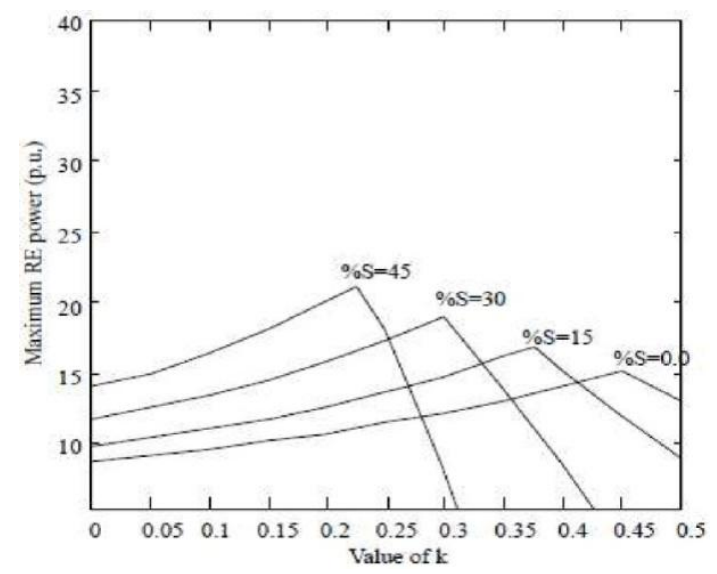

Fig 8. Variation in maximum RE power for diff. value of $\% \mathrm{~S}$.

Similarly, when $\% S=45$, we obtain the optimal location of the shunt device at $K=0.225$. A similar pattern for PRm can be observed from Figure 6 for different series compensation levels. In Figure 7, it can be observed that in the absence of series compensation $(\% \mathrm{~S}=0)$ the angle at the maximum SE power increases from $95.8 \mathrm{o}$ at $\mathrm{K}=$ 0 to its maximum value $171.1 \mathrm{o}$ at $\mathrm{K}=0.45$. When $\% \mathrm{~S}=15$ then $\delta \mathrm{m}$ increases when $\mathrm{K}$ is increased and reaches its maximum value 180.50 at $\mathrm{K}=0.375$. When $\% \mathrm{~S}=30$ then $\delta \mathrm{m}$ increases when $\mathrm{K}$ is increased and reaches its maximum value 1850 at $\mathrm{K}=0.3$ and for $\% \mathrm{~S}=45$ it is $188 \mathrm{o}$ for $\mathrm{K}=0.225$. As the degree of series compensation 
level $(\% \mathrm{~S})$ increases, the stability of the system increases and the optimal location of the shunt FACTS device changes.

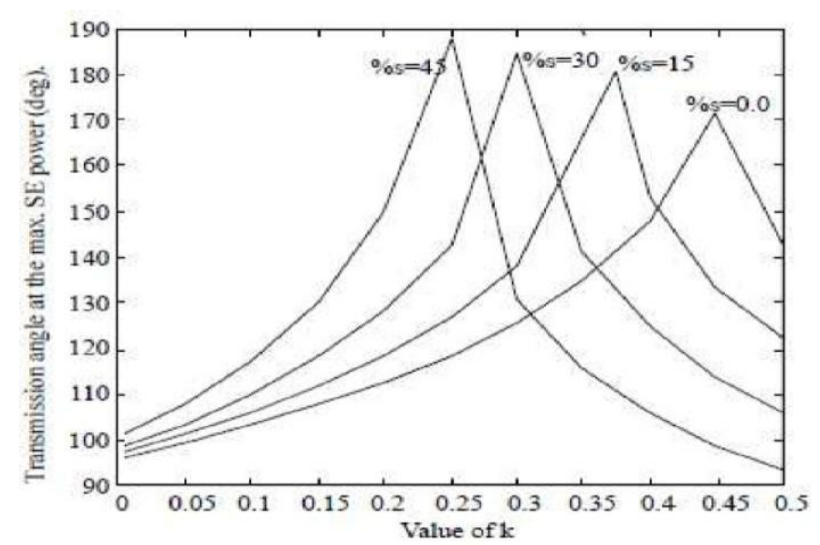

Fig 9. Variation in transmission angle at the max. SE power for diff. $\% \mathrm{~S}$

\section{Optimal Location Of Shunt Facts Devices}

Figure 8 shows the variation of the maximum RE power of section 1 (PR1m) and maximum SE power of section 2 (PS2m) against the value of $\mathrm{K}$ for different series compensation levels $(\% \mathrm{~S})$. It can be seen in Figure 8 that for an uncompensated line then maximum power curves cross at $\mathrm{K}=0.45$ and the crossing point is the transition point

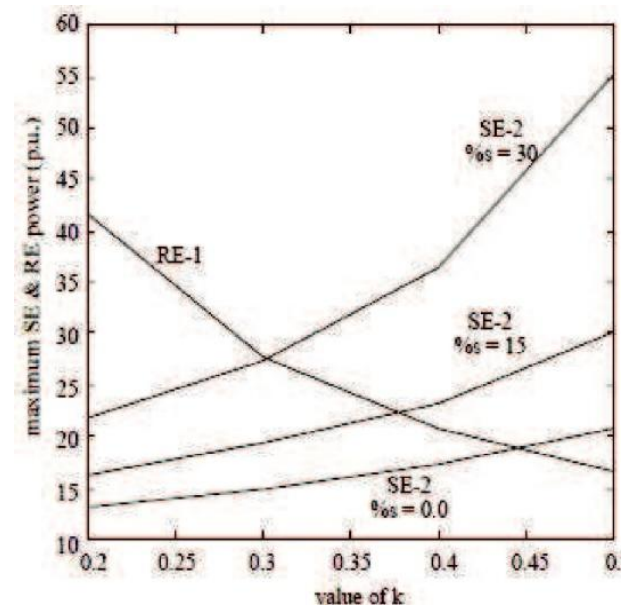

Fig 10. Variation in the maximum RE power of section-1 and SE power of section-2 against $\mathrm{k}$ for diff. value of $\% \mathrm{~S}$.

Thus, to get the highest benefit in terms of maximum power transfer capability and system stability, the shunt FACTS device must be placed at $\mathrm{K}=0.45$, which is slightly off- center. When the series compensation level is taken into account then for $\% \mathrm{~S}=15$ the maximum power curves cross at $\mathrm{K}=0.375$ and maximum power transfer capability increases. It means that when series compensation level $(\% \mathrm{~S})$ is increased then the optimal location of the shunt device shifts towards the generator side. Similarly when $\% \mathrm{~S}=30$ then the optimal location is at $\mathrm{K}=0.3$ and for $\% \mathrm{~S}=45$ it is at $\mathrm{K}=0.25$. Figure 9 shows the variation in optimal off-center location of the shunt FACTS device against the degree of series compensation level $(\% \mathrm{~S})$ for the given $\mathrm{R} / \mathrm{X}$ ratio of the line. It can be observed in Figure 9 that the optimal off-center location is $10 \%$ for the uncompensated line. When series compensation level $(\% \mathrm{~S})$ is increased than optimal off-center location increases linearly and reaches its highest value $55 \%$ for $\% \mathrm{~S}=45$. Operation of the UPFC demands proper power rating of the series and shunt branches. The rating should enable the UPFC carrying out pre-defined power flow objective. 


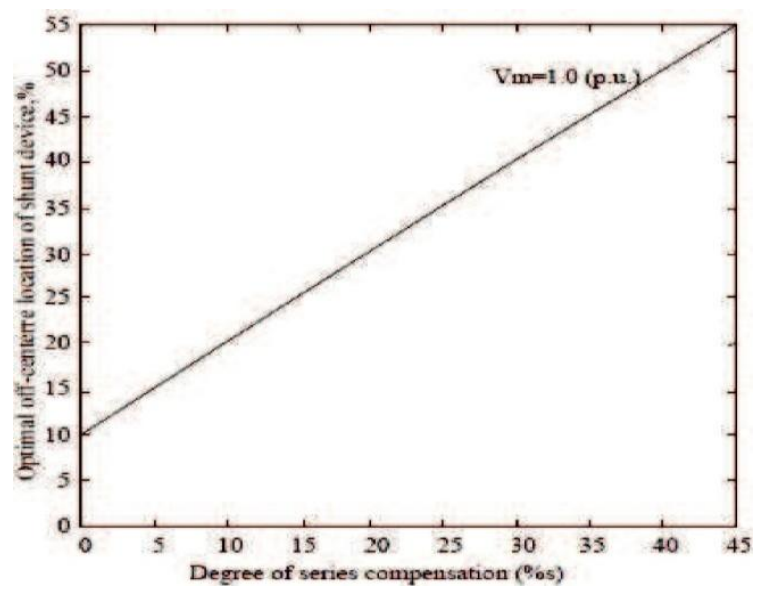

Fig 11. Variation in the optimal off-center location of shunt FACTS device against degree of compensation of line (\%S).

\section{Conclusion}

This paper investigates the effect of series compensation on the optimal location of a shunt FACTS device to get the highest possible benefit of maximum power transfer and system stability. Various results were found for an actual line model of a series compensated $345 \mathrm{kV}, 450 \mathrm{~km}$ line. It has been found that the optimal location of the shunt FACTS device is not fixed as reported by many researchers in the case of uncompensated lines but it changes with the change in degree of series compensation. The deviation in the optimal location of the shunt FACT device from the center point of line depends upon the degree of series compensation and it increases almost linearly from the center point of the transmission line towards the generator side as the degree of series compensation $(\% \mathrm{~S})$ is increased. Both the power transfer capability and stability of the system can be improved much more if the shunt FACTS device is placed at the new optimal location instead of at the midpoint of the line. The effect of SVC and STATCOM controllers in enhancing power system stability has been examined. Though both the devices can provide extra damping to the system, it has been demonstrated that STATCOM is very effective in enhancing system performance in situations where system voltages are very much depressed. Also, because of its fast response time, STATCOM control is superior to that of SVC

\section{References}

[1] Nemat-Talebi et al, SoutheastCon, 2004. Proceedings. IEEE "An efficient Power injection modeling and sequential power flow Algorithm for FACTS Devices", page(s): 97- 104. [DOI 10.1109/SECON.2004.1287904

[2] Gyugyi, L. 1995, "Unified power flow controller concept for flexible AC Transmission system", IEEE Proceedings- Volume 10, Issue 2, Apr 1995 Page(s):1085 - 1097. [DOI 10.1109/61.400878]

[3] M.H. Haque,2000, "Optimal location of shunt FACTS devices in long transmission line", IEE Proceedings on Generation Transmission \& Distribution, Vol. 147, No. 4, pp. 218-22, 2000. [DO I 10.1049/ip-gtd:20000412]

[4] Narain G. Hingorani, Laszlo Gyugyi , 1999, Understanding FACTS: Concepts and Technology of Flexible AC Transmission Systems, Wiley-IEEE Press, December 1999. ISBN 978-0-7803-3455-7

[5] N.G. Hingorani, L. Gyugyi, Understanding FACTS, Concept and Technology of Flexible AC Transmission Systems, NewY ork, Wiley, 2000.

[6] Xiao-Ping Zhang, Christian Rehtanz, Bikash Pal, 2006, Flexible AC Transmission Systems: Modelling and Control,Springer, March 2006. ISBN 978-3-540-30606-1 http://www.springer.com/3-540-30606 4

[7] A. Edris, R. Adapa, M.H. Baker, L. Bohmann, K. Clark, K. Habashi, L. Gyugyi, J. Lemay, A. Mehraban, A.K. Myers, J. Reeve, F. Sener, D.R. Torgerson, R.R. Wood, Proposed Terms and Definitions for Flexible AC Transmission System (FACTS), IEEE Transactions on Power Delivery, Vol. 12, No. 4, October 1997 [DOI 10.1109/61.634216]

[8] Giuseppe, Fusco / Mario, Russo, 2006, Adaptive Voltage Control in Power Systems: Modelling, Design and Applications (Advances in Industrial Control)? Springer | ISBN 184628564X | November 13, 2006 |

[9] P. Kundur, 1994, Power system stability and control, EPRI Power System Engineering Series, New York, McGraw-Hill Inc., 1994. 328

[10] Tate J.E and Thomas J.Overbye, 2005, "A Comparison of the Optimal Multiplier in Polar and Rectangular Coordinates" IEEE Transactions on Power systems, Vol.20,No 4, [DOI 10.1109/TPWRS.2005.857388]

[11] Tate J.E and Thomas J.Overbye, 2005, "A Comparison of the Optimal Multiplier in Polar and Rectangular Coordinates" IEEE Transactions on Power systems, Vol.20,No 4.

[12] M. Saravanan, S. M. R. Slochanal, P. Venkatesh, J. P. S. Abraham, 2007, "Application of particle swarm optimization technique for optimal location of FACTS devices considering cost of installation and system loadability”, Electric Power Syst Research, vol. 77, pp. 276-283. 


\section{About the Authors:}

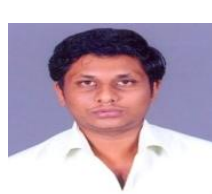

Ponnam.Yellaiah ${ }^{1^{*}}$, Asst.Professor

Was born in suryapet, nalgonda, India,in 1987. He received the B.Tech. Degree in Electrical \& Electronics Engineering from the University of JNTU, Hyderabad, India, in 2008, and M.Tech in control system from the University of JNTU-Hyderabad. He is currently Asst.Professor in EEE Department of Sri Indu College of Engineering \&Technology (Autonomous) ,Hyderabad, His currently research interests include control system, Power electronics, drives, flexible ac transmission system (FACTS), and power quality, neural networks \& fuzzy logic, PID controller.

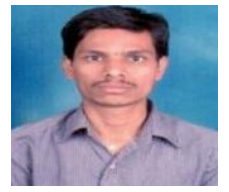

Sravan kumar.Palarapu ${ }^{2 *}$, Sr. Asst.Professor, (*Corresponding author)

Was born in nalgonda, India, in 1987. He received the B.Tech. Degree in Electrical \& Electronics Engineering from the University of JNTU, Hyderabad, India, in 2008, and the M.Tech. Degree in power electronics from the University of JNTU, Hyderabad, India, in 2011 in 2012, he joined the Department of Electrical \& Electronics Engineering, as a Sr. Asst.Professor in (ASTRA) Aurora Scientific Technological \& Research academy His current research interests include power electronics, drives, active filters, flexible ac transmission system (FACTS), and power quality.

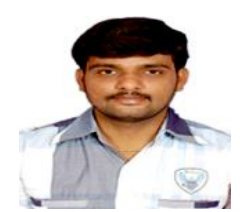

Kumar.Keshamoni ${ }^{3 \#}$, Asst.Professor

Received B.Tech degree in Electronics and Communication Engineering from the University of JNTU and Pursuing M.Tech degree in VLSI from the University of JNTU-Hyderabad. He is currently Asst.Professor in ECE Department of RVR Institute of Engineering \& Technology, Hyderabad, and he is an Editorial board member for IJEATE-Journal (International Journal of Emerging Technology and Advanced Engineering with ISSN 2250-2459) IJETAE-Journal (International Journal of Advancements in Research \& Technology with ISSN 2278-7763), His currently research interests include VLSI Design, Nano Technology and Embedded Systems. 